\title{
Local Farmer's Perspective on Actual and Perceived Cost of Sustainable Land Management and Its Economic Viability: A Case Study of Mali
}

\author{
Mamoudou Ibrahima Sall ${ }^{*} \quad$ Yang Shu $^{2}$ \\ 1.School of Economics, Huazhong University of Science and Technology, 1037 Luoyu Road, Wuhan, 430074, \\ P.R. China \\ 2.School of Economics and Trade, Hunan University, Lushan S. RD, Changsha, Hunan, China
}

\begin{abstract}
The sustainable land management (SLM) is a vital parameter to efficiently manage the agricultural practices with more benefits. The economic viability of SLM explained the efficient cost/benefit analysis that was currently needed. This study recognizes the costs of SLM analyse the benefits and then equate both of them in order to provide its economic viability. The quantitative methods were developed with a questionnaire; data was collected from Malian people. The quantification of the data showed the considerable experience as well as the commitment of people in SLM after well knowing about its costs and benefits. Although the cost of farming practice was increased and collective of farming output was amplified more proportionally than farming cost. The overall rewards of increased income economic disparities, diversity, long-term returns, short-term returns and farm management as well the decreased farm workload effective proved incentives for farmers. The pragmatic evidences will help the government to make SLM into practice and act as a reference for future researchers.
\end{abstract}

Keywords: Sustainable land management, economic viability, costs, productivity, benefits analysis

DOI: $10.7176 /$ PPAR/9-12-04

Publication date: December $31^{\text {st }} 2019$

\section{Introduction}

Sustainable land management is referred to the efficient management of land, plants, animals, soil, and water in order to fulfil the demands of the modern human society while at the same time maintaining that sustainability of natural resources. It takes account of all human activities that are concerned with the natural resource exploitation e.g. farming, mining, housing as well as planning and development. It also encompasses the measures of water, vegetation, and soil conservation for achieving an increased productivity. While talking about the sustainability, it is not just the protection of resources it is about conservation of resources with an economic viability. Due to increased concerns of resource depletion and future stability, many countries of the world are opting for sustainable land management (SLM).

Many of the environmental and economic benefits have been achieved through SLM and many researches in the past have also revealed its feasibility with respect to cost benefit analysis. It started as an individualistic action and then root in the whole farmer's community with the purposes of saving environment and future sustainability. In this way, environmental degradation is minimized and also dry areas can be rehabilitated as the effective and efficient utilization of natural resources is existed. Farmer community was maximum benefited by terracing practice as it helps to maintain the good soil structure. Moreover, the creation of terraces and bunds are in harmony with the area specifications. Apart from this, it also facilitates the farmers to enhance the output of their farms in terms of fruits and vegetables e.g. bananas, watermelon, strawberries, mangoes, lemons, spinach, carrots, ginger, onions etc. Along with all these benefits the cost of the soil erosion is also worthy to consider.

The cost of labor's opportunity and credit are also area specific. However, the limited credit can be an inhibiting factor for the practices of SLM by farmers in rural areas. Moreover, the return period of the benefits and yield are also very long that farmers cannot afford to wait for, as they also have their own needs. Another limitation is the capital needs to apply SLM practices that famers usually can't afford, so, the only option is the loan from institutions that is an addition cost to be considered.

Although a lot of work has already been done on SLM, still it is unclear that if the cost of SLM is more than its benefits. This is a cause that people from all over the world repel this practice and has a perception that this is a costly practice. The similar situation in Mali endorsed the need of research in this area. However, previous works of Eswaran and Blum have explained that it is not a domestic problem but a global issue as well. The practice of sustainable land is approached as a solution of nature melioration but it is not seen often with a view point of cost to benefit. In future, if this problem is not addressed the resources of nature will no longer be available for next generation. Therefore, this paper is aimed at the cost and benefit analysis of land management with its different concepts and approaches as well.

In near past, most of the work has been done on the implications of sustainable land management but cost to 
benefit analysis still remained unaddressed. A number of benefits and costs are established for SLM. Many of the investigators such as Kundzewicz \& Kowalczyk have presented a qualitative model on this particular issue but its quantitative aspects are still missing. In the current study, an attempt has been made to fulfil this gap in Mali's land management system. The decision of applying SLM practices differs with the economic conditions of the country. So, anther objective of this study is to elaborate the viability of SLM in Mali's economic set up. Theoretically, this study is significant as it may help the people all around the world for comparing costs and benefits of SLM and can be used a reference in SLM. Practically, the SLM is proposed as a guiding tool for farmers to analyse its costs and benefits systematically and then make a decision conferring that either they should implement SLM or not. Furthermore, by applying the practices of SLM, the flood can be controlled and avoided as well. As the cost and benefits of SLM are not analyzed before, so the government can perceive its costs and benefits through this research to form policies allied with SLM.

\section{Literature Review}

Many definitions, types, approaches, concept, costs, and benefits of SLM have been discussed in this section. It is referred to the operative management of land with no effect on its biodiversity and ecological balance. The biodiversity is a complex network of animals, plants, and human beings in this word's ecosystem and integrity of the ecosystem is to defend changes that are imparted to it by external sources. The maintenance of the ecosystem is based on natural capital that includes air, ocean, fresh water, conservation of soil, and forests.

The economic feasibility of SLM relies on a number of aspects such as expenditures, income, the stability of earnings, nature, output generated on farm, and quality. The term SLM has been explained in previous studies to include different approaches such as using artificial agriculture systems, demolishing tropical forests, and expansion of urban areas, humans are altering the earth's integrity. However, the aspects of land-use are diverse in every fragment of the world, but their final result may persist undistinguishable, like obtaining natural resources to fulfil the requirements on instant basis and generating fibre and food for a rising population.

The LM is vital for fulfilling the desires and needs of human beings and also for dousing the natural ecosystem of the current world. If the land is used improperly then numerous negative concerns may arise such as deprivation of land and climate change as well as the lesser food production and services. However, many costs are needed for application of the SLM e.g. opportunity cost of labor and credit cost of labor.

From the past few decades, researchers have observed that farmers and land directors have been fruitful in increasing the per capita production of food and in dipping the prices of food. All these actions are completed through the application of technologies and new approaches. But currently it has been observed that in developed zones of the world, the increase in the agricultural output has reduced the prices of utilities which in turn have lowered the profit limits of farmers in an economic prospect. Yet, these issues may not be effective for the future and additionally what is sustainable nowadays may not be sustainable in upcoming days and moreover, sustainability of land differs from area to area as well.

There are few aims on which the construction of SLM positions such as acceptability protection, security, viability, and productivity. Literature has defined that productivity is receiving the return from SLM by proficient land utilization and productivity increment. The studies conducted past have clarified practicality that if the land does not have economic feasibility, then it cannot be utilized and preserved for long time. Then investigators have pin pointed that the protection of natural resources and species of plants and animals for future generations is very crucial. Moreover, the level of production peril should be concentrated and the capability of the soil should be improved. Finally, the land used must be communally acceptable. Up till now these points are not being implemented competently.

Many activities are involved in SLM e.g. enhancing and conserving the production purposes of forestland, cropland and grazing land such as upland areas, flatlands, down-slope regions and bottomlands. At that point, it also helps to preserve the productive zones of forest that include profitable as well as non-profitable assets of the forests. Moreover, it also safeguards to uphold the requirements of hydropower production and regions of hydrosphere conservation. In addition to this, the requirements of farms and further accomplishments of production are also sustained by aquifers. However, the cost and benefit analysis are still lacking.

Moreover, SLM is also effective for reclamation of the land that is degraded as a result of massive production activities. This is very crucial especially in those areas where needs growing population has increased the burden on land resources and in as well uplands that suffer massive land degradation by activities e.g. watershed, erosion, weathering etc. But still the adverse effects on land cannot be controlled through SLM but it is type of a management that offers continuous reversal of these effects.

As a process, SLM has many principles e.g. it follows participatory approaches and driven land user, consuming the natural resources of earth in an integrated manner for ecosystem protection and farming practices, and participation of multi-stakeholders at multilevel with the support of organizations and generation of revenue at for locals.

With the climate change, the social prestige of changing population, growing population, ever rising prices 
of commodities. As a result, there is massive utilization of land and the approaches to address these issues need as it is crucial to integrate agriculture, water management, forestry, and urban planning. This can be an only way for land sustainability. The crucial is to implements such reforms with caution.

The SLM benefits farmers in terms of biodiversity protection, soil conservation, effectiveness of tillage regimes and intensification. The grass strips, terraces, and bunds protect soil losses (erosion) as result farmers are also benefited. Many studies have been conducted on the importance of these above-mentioned aspects in different areas of the world.

The reduced tillage regime is proven to be advantageous for farmers as it incurs less investment than terraces. The seedbeds tillage not only controls the parasitic and pest infestations in the crop field but also works for the mineralization to enhance soil quality that results in increased production of lentils, apples, apricots, fababeans, vegetables etc. Apart from this, erosion and run-off are also reduced. But still these processes are area specific and can pose different aspects with of soil structure and labor requirement accordingly.

Additional benefit of SLM is the escalation of pesticides, capital, labor, feeds, the crop residue and minerals, etc. to increase the land productivity. By integrating the agronomic practices with SLM, the nutrients of soil are increased. The suitable utilization of non-organic or organic fertilizers upsurges the long-term production and soil structure. Farmers can adjust the system of agriculture to attain more productivity from the land.

Escalation also includes irrigation arrangement which delivers water to all the fields including the dry-lands so that farmers can grow cash crops here as well. The irrigation is not solely responsible for the enhanced soil production e.g. it cannot improve soil structure alone. So, other factors are also needed to be considered.

Another advantage of SLM is biodiversity protection. Agriculturalists can do farming in various environments and also distinct types of foods can be cultivated. Furthermore, the genetic assets of the plant are not accessible on one farm, so these are also essential to be replaced. Thus, a diverse genomic population is desirable. The tough environmental conditions may be a limiting factor in the seed availability.

The benefits of SLM on the global level comprise carbon retention, climate mitigation, genetic materials' conservation, and flood control. The quantity of carbon can be easily determined in the environment, and flood can also be organized when the soil structure relics strong enough. However, to gain, these paybacks farmers have to capitalize a lot.

For the application of SLM, farmers and land executives have to experience costs as well. The price of credit and opportunity are incurred when this exercise is performed, according to many researchers. If the credit is inaccessible, then farmers cannot apply the methodologies of SLM, as a result, the cost of borrowing accompanied with interest rates are higher are incurred. Furthermore, cost of labor increases during productive periods even it is available as well. Still, both the labor credit cost and opportunity cost are area specific.

Then one more type of cost is labor cost incurred at the time of installation of SLM activities. Finally, the costs of land deformation are also there while installing the SLM program. The positive results of SLM are achieved after payback period but land degradation costs are immediate, so it's a vital problem for farmers to wait for a long time.

\section{Material and Methods}

The research design, research approach, research philosophy, time zone, sampling, population study, sampling size, data collection, questionnaires, ethical considerations and validity, have been solicited with distinct advantages and disadvantages. 'The exploratory research design' is used in the current study to perform the comparative analysis of costs and benefits incurred by SLM practices. This type of research strategy is extensively used to find new insights of SLM. Researchers have confirmed that exploratory research aids to get different views and interpretations of different people. It is further emphasized that it helps in exploring all possible routes of incurred costs. The designs fulfil the requirements of the current study along with intervention of the economic feasibility of SLM with respect to increased benefits and relatively fewer costs.

Statistical analysis was performed in this study for quantifiable observations. Moreover, the philosophy of positivism states that it is more important for the researchers to emphasis on facts rather than on views.

The deductive approach was employed in this study to acme the study traits from general to specific. Furthermore, it is a hypothesis-based study, so research plan was formed accordingly. The quantitative method was employed to analyse the data by concentrating on the numerical and statistical scrutiny of the data, which was gathered through surveys, ballots, and questionnaires. It collects the statistical data to elucidate a specific subject or occurrences. The technique was used to equate the benefits of SLM with associated costs.

In order to collect the relevant data, the residents of Mali (latitudes $10^{\circ} \mathrm{S}$ and $25^{\circ} \mathrm{N}$, and longitudes $13^{\circ} \mathrm{W}$ and $5^{\circ} \mathrm{E}$ ) were selected. The farmers or people related to agriculture were the study population of our research. The native people were selected as sample population as they are more alert of the costs and benefits of SLM in Mali. According to some investigators, sampling means selection of the people as a representation of the whole population. This study was conducted with purposive sampling; i.e. the sample was being chosen in accordance with the aims of the study and the characters of the study population. To collect the data, 176 volunteers were 
selected from all over the Mali.

The data was obtained through both primary and secondary methods to enhance the validity of the study. A self-constructed questionnaire was used to collect the data from the sample. Each questionnaire was to confine 12 questions in total and 9 questions were in the objective phase and 3 questions were in the demographic phase. Multiple options were provided along with the queries and respondents chose the best suited option. The total 150 questionnaires were obtained back overseen for validity requirements.

The ethical values were compiled in this study proficiently. Informed consent was taken from the participants before meeting for questionnaires. Moreover, the confidentiality of respondents was also preserved.

\subsection{Results}

\subsection{Demographic Analysis}

It was observed that males were engaged to the SLM in Mali. In a sample size of 176 individuals, $68.2 \%$ were males and only $31.8 \%$ were females (Fig 1A) that paid more focus to the exercise of SLM and equated its benefits against its costs. This describes the gender-based specificity that women mostly perform household and less sensitive tasks while man do sensitive and more crucial jobs in society such as implementation of SLM practices.
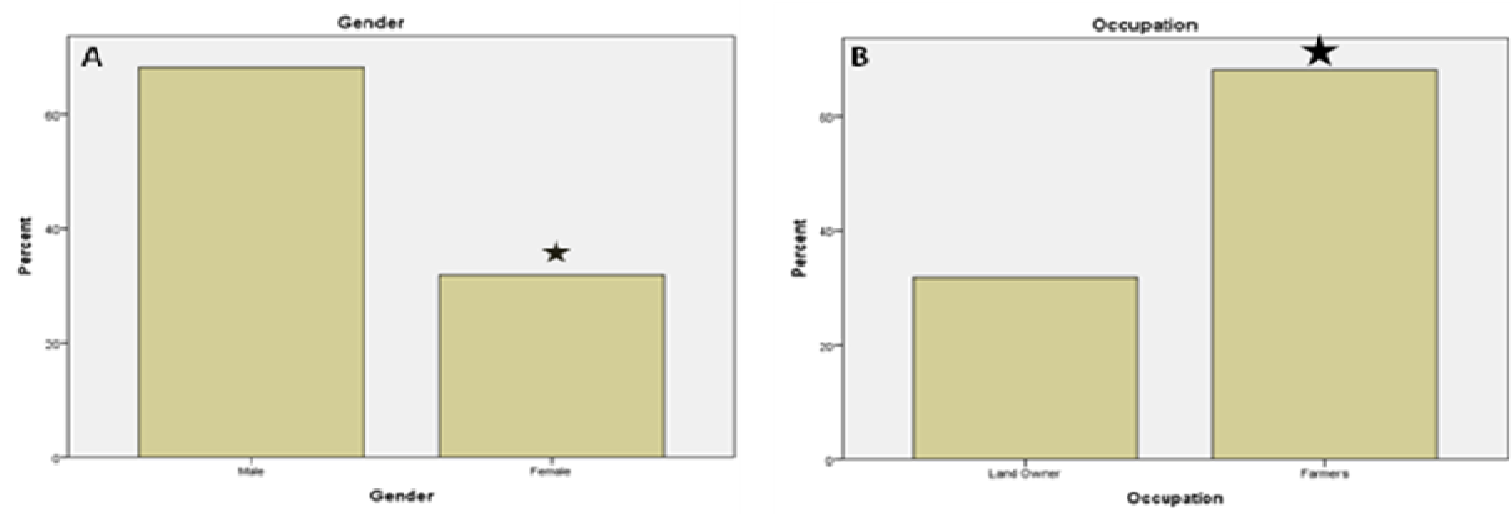

\section{C}
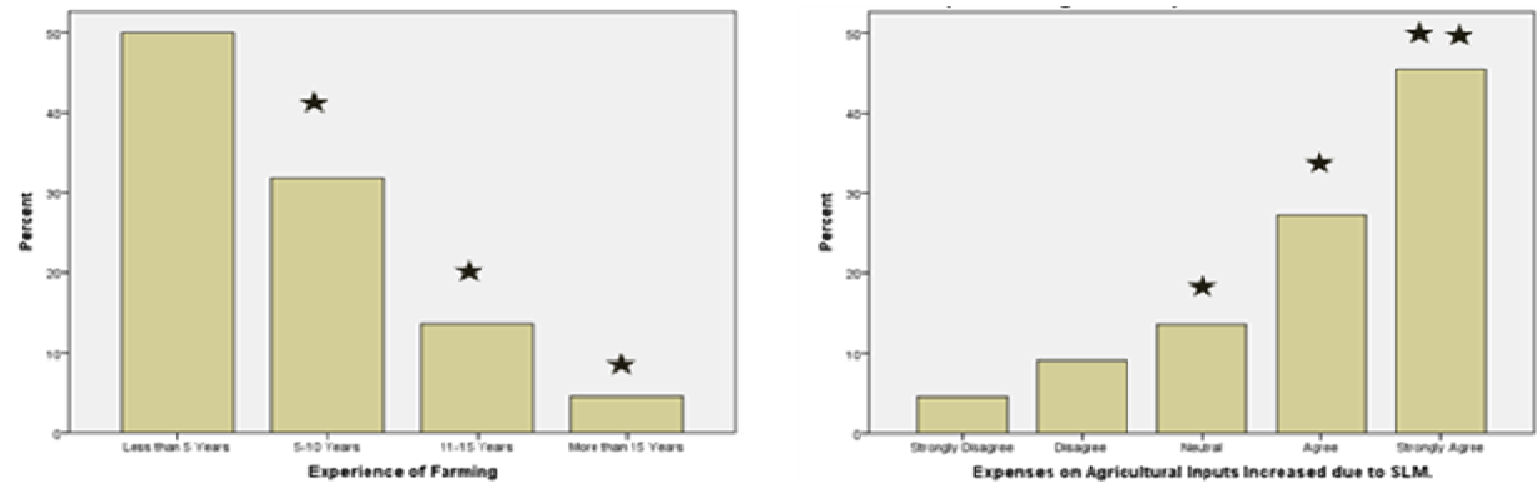

Figure 1. (A)The gender based engaament of indiciduals in sustainabale land management. (B) The distribution of occupation of sample population. (C) The duration of farming experience of individuals practicing sustainable land management. (D) The survey of samples mindset towards the SLM as the basic cause for increasing the agricultural inputs.

Most of the participating volunteers were farmers (68.2\%) instead of land-owners (31.8\%), as shown in Fig. 1B. It was also depicted that land-owners were not as much interested the SLM practices, they are more ownership centered, as the farmers were as they are bound give the fixed share/money to land-owners.

Most of the farmers $(50 \%)$ were also young and had agricultural experience of about 5 to 10 years while only $13.6 \%$ had a practice of 11-15 years (Fig-1C). The most of individuals (farmers and land-owners) were fount unaware regarding to the SLM practice and its profits and costs due to less experience. The results of this study highlight the increasing trend of farmers to implement the SLM for soil improvement and well household.

\subsection{Descriptive Costs and Benefits Analysis}

The $45.5 \%$ of the volunteers were strongly agreed that expenses in the form of agricultural inputs amplified due 
to SLM whereas only $4.5 \%$ intensely disagreed with this statement (Fig 1D). It was elaborated that land-owners and farmers have to bear expenses and costs incurred while implementing the SLM approach (Table 1). According to them, the costs of SLM are more than its paybacks, but in long run it is more beneficial for sustainable agriculture. Meanwhile, $13.6 \%$ gave an impartial answer.

Table 1. The farmer's consideration of SLM as the reason for increasing the cost of agricultural inputs

\begin{tabular}{|l|l|r|r|r|r|}
\hline \multicolumn{1}{|c|}{} & Frequency & Percent & Valid Percent & Cumulative Percent \\
\hline \multirow{5}{*}{ Valid } & Strongly Disagree & 8 & 4.5 & 4.5 & 4.5 \\
\cline { 2 - 6 } & Disagree & 16 & 9.1 & 9.1 & 13.6 \\
\cline { 2 - 6 } & Neutral & 24 & 13.6 & 13.6 & 27.3 \\
\cline { 2 - 6 } & Agree & 48 & 27.3 & 27.3 & 54.5 \\
\cline { 2 - 6 } & Strongly Agree & 80 & 45.5 & 45.5 & 100.0 \\
\cline { 2 - 6 } & Total & 176 & 100.0 & 100.0 & \\
\hline
\end{tabular}

The 36.4\% were agreed that farm income has been increased by SLM but 9.1\% strongly disagreed with this argument (Fig 2A, Table-2). The findings demonstrated that the benefits of SLM are more than expenses incurred as it assists the farmers as well as land-owners to acquire benefits from it in the form of productivity, diversity and short-term profits etc.

Table 2. The farmers' views toward the farm income increased due to SLM

\begin{tabular}{|l|l|r|r|r|r|}
\hline \multicolumn{1}{|c|}{} & Frequency & Percent & Valid Percent & Cumulative Percent \\
\hline \multirow{5}{*}{ Valid } & Strongly Disagree & 16 & 9.1 & 9.1 & 9.1 \\
\cline { 2 - 7 } & Disagree & 24 & 13.6 & 13.6 & 22.7 \\
\cline { 2 - 7 } & Neutral & 16 & 9.1 & 9.1 & 31.8 \\
\cline { 2 - 6 } & Agree & 64 & 36.4 & 36.4 & 68.2 \\
\cline { 2 - 6 } & Strongly Agree & 56 & 31.8 & 31.8 & 100.0 \\
\cline { 2 - 7 } & Total & 176 & 100.0 & 100.0 & \\
\hline
\end{tabular}

The $59.1 \%$ of were disagreed with the query that multiplicity of income has reduced due to SLM. But $9.1 \%$ provided a neutral reply whereas only $4.5 \%$ intensely agreed with this statement (Fig $2 \mathrm{~B}$ ).

A
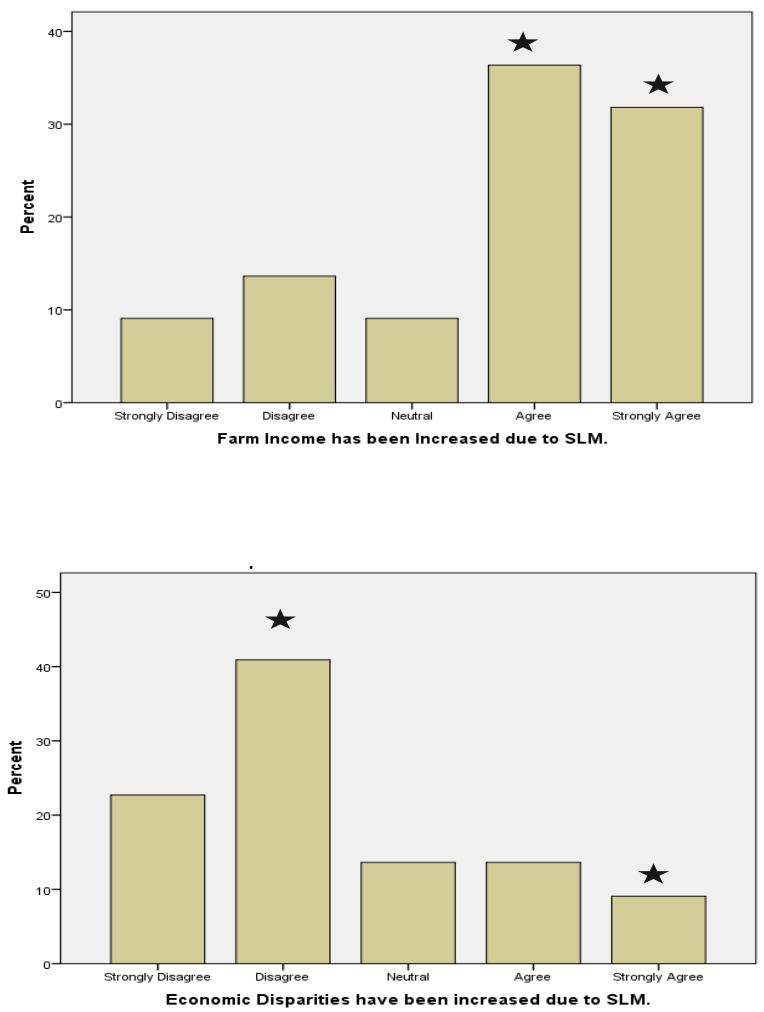

$\mathrm{C}$
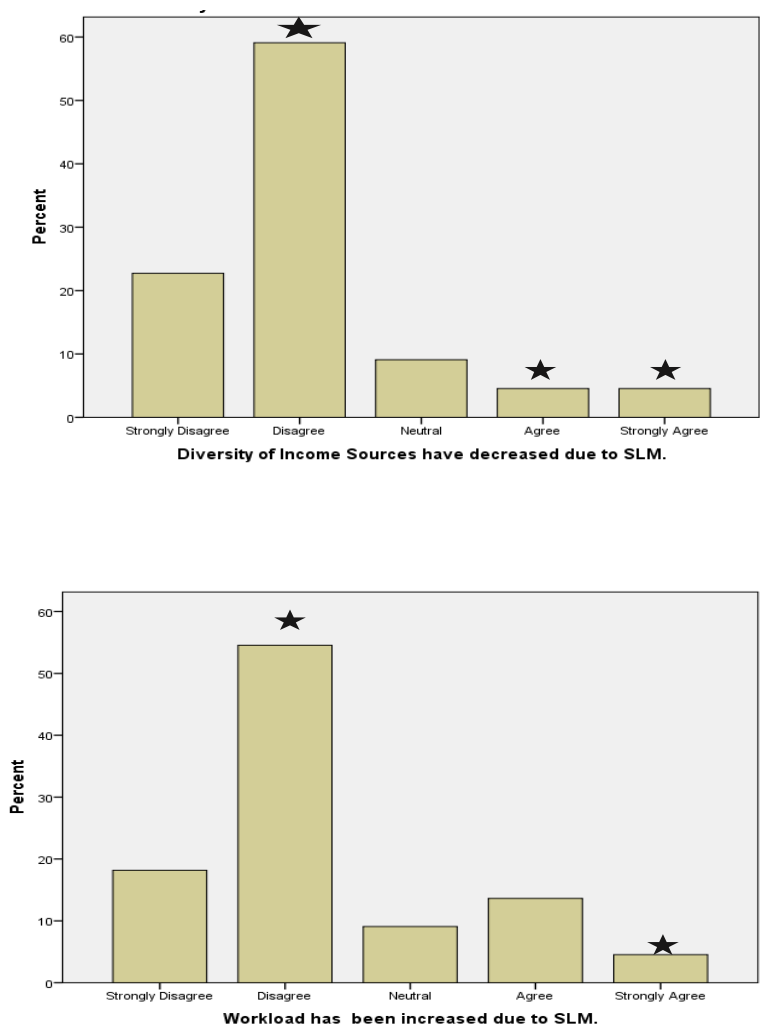

D

Figure 2. (A) The distribution of farm income due to the application of SLM. (B) The sample population response towards the decrease of income source diversity due to SLM. (C) The economic disparities increased due to SLM. (D) Work load has been increased due to SLM. 
The results revealed that by SLM methodology, diversity of income is augmented. So, it exposed that its cost was lesser than its integrated benefits (Table 3).

Table 3. The farmer's consideration toward the decrease of income source diversity due to SLM

\begin{tabular}{|c|c|c|c|c|c|}
\hline \multicolumn{2}{|c|}{} & Frequency & Percent & Valid Percent & Cumulative Percent \\
\hline \multirow{5}{*}{ Valid } & Strongly Disagree & 40 & 22.7 & 22.7 & 22.7 \\
\cline { 2 - 6 } & Disagree & 104 & 59.1 & 59.1 & 81.8 \\
\cline { 2 - 6 } & Neutral & 16 & 9.1 & 9.1 & 90.9 \\
\cline { 2 - 6 } & Agree & 8 & 4.5 & 4.5 & 95.5 \\
\cline { 2 - 6 } & Strongly Agree & 8 & 4.5 & 4.5 & 100.0 \\
\cline { 2 - 6 } & Total & 176 & 100.0 & 100.0 & \\
\hline
\end{tabular}

As far as economic disparities are concerned, $40.9 \%$ were disagreed that economic with that disparities have been increased by SLM practices (Fig 2C). Only 9.1\% were strongly agreed and $13.6 \%$ were neutral as they were not cognizant of the costs and profits of SLM. But those who disagreed were aware of the fact that economic inequalities did not upsurge due to SLM. Likewise, $22.7 \%$ were strongly disagreed and only $13.6 \%$ agreed in harmony with their skills (Table 4).

The $54.5 \%$ of respondents were disagreed with the statement that the workload has been increased by executing the SLM method (Fig 2D). However, 9.1\% provided a neutral answer for this particular question while only $4.5 \%$ were strongly agreed with it. It was revealed that SLM has reduced the workload of farmers by refining the soil structure and by escalating the feeds, capital, seeds and minerals in the fields (Table-5).

Table 4. The consideration of farmers toward the increase of economic disparities due to SLM

\begin{tabular}{|c|c|c|c|c|c|}
\hline \multicolumn{2}{|c|}{} & Frequency & Percent & Valid Percent & Cumulative Percent \\
\hline \multirow{5}{*}{ Valid } & Strongly Disagree & 40 & 22.7 & 22.7 & 22.7 \\
\cline { 2 - 6 } & Disagree & 72 & 40.9 & 40.9 & 63.6 \\
\cline { 2 - 6 } & Neutral & 24 & 13.6 & 13.6 & 77.3 \\
\cline { 2 - 6 } & Agree & 24 & 13.6 & 13.6 & 90.9 \\
\cline { 2 - 6 } & Strongly Agree & 16 & 9.1 & 9.1 & 100.0 \\
\cline { 2 - 6 } & Total & 176 & 100.0 & 100.0 & \\
\hline
\end{tabular}

Table 5. The farmers consideration of SLM as the reason of increasing the work load of the farms

\begin{tabular}{|c|c|c|c|c|c|}
\hline \multicolumn{2}{|c|}{} & Frequency & Percent & Valid Percent & Cumulative Percent \\
\hline \multirow{5}{*}{ Valid } & Strongly Disagree & 32 & 18.2 & 18.2 & 18.2 \\
\cline { 2 - 6 } & Disagree & 96 & 54.5 & 54.5 & 72.7 \\
\cline { 2 - 6 } & Neutral & 16 & 9.1 & 9.1 & 81.8 \\
\cline { 2 - 6 } & Agree & 24 & 13.6 & 13.6 & 95.5 \\
\cline { 2 - 6 } & Strongly Agree & 8 & 4.5 & 4.5 & 100.0 \\
\cline { 2 - 6 } & Total & 176 & 100.0 & 100.0 & \\
\hline
\end{tabular}

The short-term benefits are also important aspect of SLM that were disagreed by $40.9 \%$ (Fig $3 \mathrm{~A}$ ) and agreed by $18.2 \%$ agreed of the respondents while $9.1 \%$ merely gave a neutral response. It was brought into view that farmers thought that the initial cost of launching SLM was much more than its short-term profits or paybacks. 


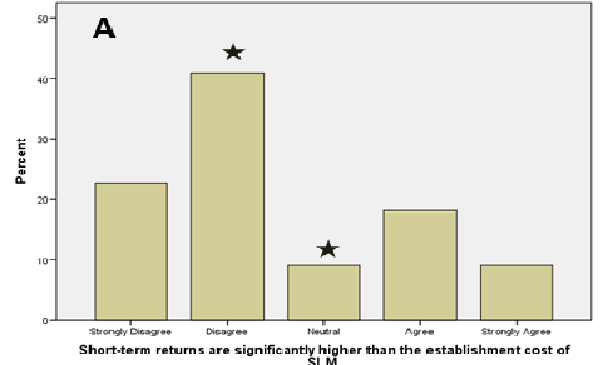

C

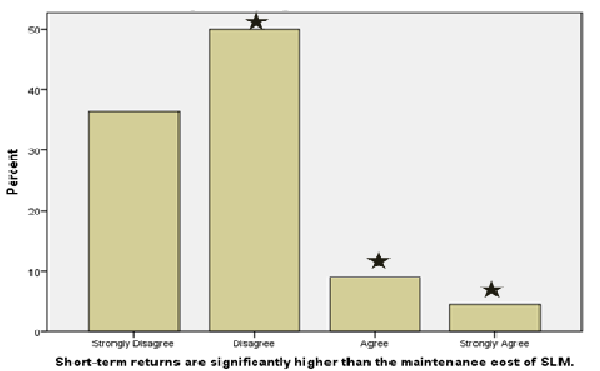

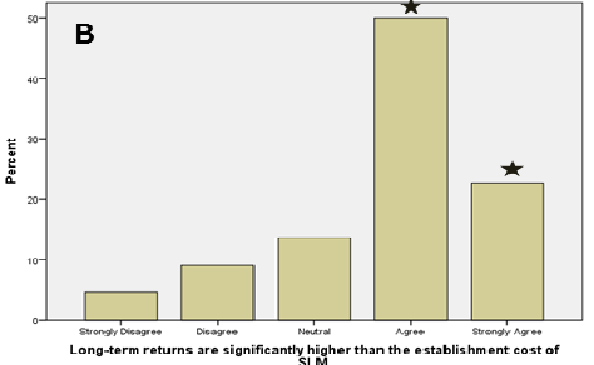

D

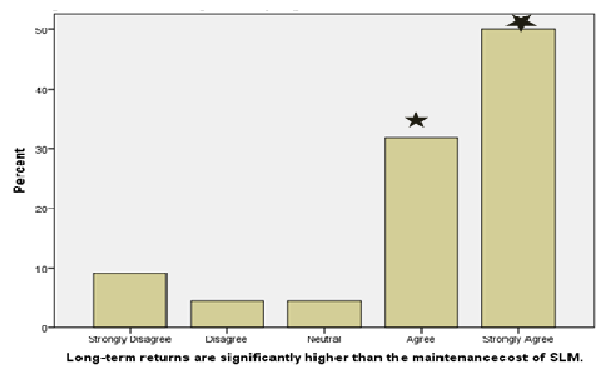

Figure 3. (A) Short term returns are significantly higher than the establishment cost of SLM. (B) long terms returns are significantly higher than the establishment cost of SLM. (C) Short term returns are significantly higher than the maintenance cost of SLM. (D) Long-term returns are significantly higher than the maintenance of SLM.

The $50 \%$ of participants in the study approved that long-term revenues are significantly greater than the SLM's application cost (Fig 3B) while 4.1\% sturdily disagreed with the query and $13.6 \%$ provided a neutral response as they might not be capable of analyzing costs and benefit ratio of SLM. However, the verdicts had revealed that farmers were able to guise beyond the initial cost of SLM and were alert that in future SLM would be advantageous for them in diverse forms.

The above results emphasized that $50 \%$ were disagreed that interim revenues are greater than the maintenance cost of SLM (Fig 3C). But the enduring respondents of the study gave dissimilar responses agreeing with their knowledge, and farming skills e.g. $4.5 \%$ were strongly agreed, $9.1 \%$ agreed, and $36.4 \%$ strongly disagreed. The 50\% have awareness that SLM's maintenance cost was greater than then its short-term revenue.

Table 6. The short-term returns are significantly higher than the establishment cost of SLM

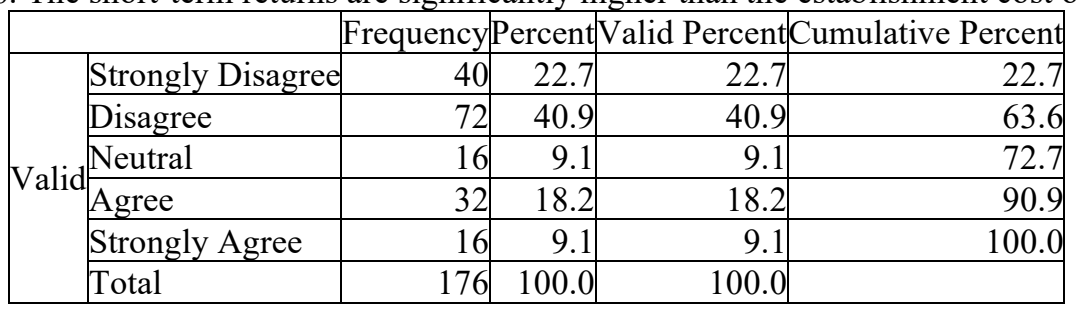

The $50 \%$ of respondents were strongly agreed that long-term yields and benefits of SLM are greater than its maintenance expenses (Fig 3D).

Table 8. Short-term returns are significantly higher than the maintenance cost of SLM

\begin{tabular}{|l|l|r|r|r|r|}
\hline \multicolumn{2}{|c|}{} & Frequency & Percent & Valid PercentCumulative Percent \\
\hline \multirow{4}{*}{$\begin{array}{l}\text { Valid } \\
\text { Strongly Disagree }\end{array}$} & 64 & 36.4 & 36.4 & 36.4 \\
\cline { 2 - 6 } & Disagree & 88 & 50.0 & 50.0 & 86.4 \\
\cline { 2 - 6 } & Agree & 16 & 9.1 & 9.1 & 95.5 \\
\cline { 2 - 6 } & trongly Agree & 8 & 4.5 & 4.5 & 100.0 \\
\cline { 2 - 6 } & Total & 176 & 100.0 & 100.0 & \\
\hline
\end{tabular}

Conversely, $9.1 \%$ strongly disagreed $4.5 \%$ replied were with a neutral response. Most of them have analyzed the SLM's benefits alongside its costs and alleged that its benefits were predicted to be more than its costs.

\section{Discussion}

The results from the data scrutiny revealed that farmers were aware of expenses required for the SLM. Furthermore, it was further inferred that the short term returns of SLM were lower than its installation and 
maintenance cost

Table 7. Long term returns are significantly higher than the establishment cost of SLM

\begin{tabular}{|c|c|c|c|c|c|}
\hline \multicolumn{2}{|c|}{} & Frequency & Percent & Valid Percent & Cumulative Percent \\
\hline \multirow{5}{*}{ Valid } & Strongly Disagree & 8 & 4.5 & 4.5 & 4.5 \\
\cline { 2 - 6 } & Disagree & 16 & 9.1 & 9.1 & 13.6 \\
\cline { 2 - 6 } & Neutral & 24 & 13.6 & 13.6 & 27.3 \\
\cline { 2 - 6 } & Agree & 88 & 50.0 & 50.0 & 77.3 \\
\cline { 2 - 6 } & Strongly Agree & 40 & 22.7 & 22.7 & 100.0 \\
\cline { 2 - 6 } & Total & 176 & 100.0 & 100.0 & \\
\hline
\end{tabular}

Previous study of Hollins and Josephi has also revealed that farmers were aware of these expenses i.e. they were able to identify the costs of SLM that was incurred on them

Table 9. Long term returns are significantly higher than the maintenance cost of SLM

\begin{tabular}{|l|l|r|r|r|r|}
\hline & Frequency & Percent & Valid Percent & Cumulative Percent \\
\hline \multirow{5}{*}{ Valid } & Strongly Disagree & 16 & 9.1 & 9.1 & 9.1 \\
\cline { 2 - 6 } & Disagree & 8 & 4.5 & 4.5 & 13.6 \\
\cline { 2 - 6 } & Neutral & 8 & 4.5 & 4.5 & 18.2 \\
\cline { 2 - 6 } & Agree & 56 & 31.8 & 31.8 & 50.0 \\
\cline { 2 - 6 } & Strongly Agree & 88 & 50.0 & 50.0 & 100.0 \\
\cline { 2 - 6 } & Total & 176 & 100.0 & 100.0 & \\
\hline
\end{tabular}

The results of data analysis confirmed that farmers were capable of analyzing the benefits of SLM. Most of the participants stated that income was increased after executing SLM. Past studies have also presented the similar findings. Moreover, farmers are also aware of the fact that variety of sources will also be improved by SLM that is a more proficient and longer run benefit.

The farmer and land owners, both were found to compare short-term as well as the long-term pay back of with the maintenance cost and installation cost of SLM. They were aware of the job-load did not upsurge with the SLM practice, but rather it aided them to do agriculture more professionally and efficiently. The former researchers also revealed the same inferences related to this particular subject.

\section{Conclusion and Future Aspects}

After the conception to its completion, finally, the findings from data analysis leads to a conclusion that the people of Mali were aware of the benefits and costs of SLM. The study has provided theoretical support through its benefits and increased the literature review in this particular domain. The empirical suggestion which is placid from the quantitative analysis has shaped concreteness in the arguments of the current study. In future, this concreteness can be used by other researchers to propose various theories for SLM. In practical aspects, this study will also help the farmers and land-owners in farming practices with an increased profit, returns, and productivity through SLM. It will create awareness among them that SLM approach will reduce physical effort in farming, and also through this, the productivity in farming will be improved. Additionally, the long-term benefits of SLM will encourage the farming industries to adopt it and change their pattern.

The government can also use this study to apply uniform rules or polices on all farmers. The increases GDP thus resulted will also upsurge the economy. This study contains number of limitations e.g. very small sample size, generalized findings to the whole population, compromised validity and reliability and use of quantitative method.

The quantitative method only enumerated the results but failed to deliver a descriptive analysis approach. Then, this study was cross-sectional and was piloted only once which preordained that it failed to get views from the respondents over a period of time. In addition, this study only circled around the costs and benefits analysis of SLM and overlooked all other aspects. This study also lacks mediators and moderators, another limitation of the study. In future more descriptive studies with larger population size are required in this field with the consideration of time series as well.

\section{References}

Duval, M. E., Galantini, J. A., Martínez, J. M., López, F. M., and Wall, L. G. 2016. "Sensitivity of different soil quality indicators to assess sustainable land management: Influence of site features and seasonality." Soil Tillage Res 159 (2): 9-22.

Schwilch G, Liniger HP, and Hurni H. 2014. "Sustainable land management (SLM) practices in drylands: how do they address desertification threats? Environ. Manag 54 (3): 983-1004.

Almagro, M., De Vente, J., Boix-Fayós, C., García-Franco, N., De Aguilar, J. M., González, D., and MartínezMena, M. 2016. "Sustainable land management practices as providers of several ecosystem services under rainfed Mediterranean agroecosystems." Mitigation and adaptation strategies for global change, 21 (7): 
1029-1043.

Giger, M., Liniger, H., Sauter, C., and Schwilch, G. 2018. "Economic benefits and costs of sustainable land management technologies: an analysis of WOCAT's global data." Land. degrad. dev 29 (4): 962-974.

Gray, J. M., Chapman, G. A., \& Murphy, B. W. "Land management within capability: a new scheme to guide sustainable land management in New South Wales, Australia." Soil Res 2015, 53 (6): 683-694.

Brevik, E. C.Pereira, P., Muñoz-Rojas, M., Miller, B. A., Cerdà, A., Parras-Alcántara, L., \& Lozano-García, B. 2017. "Historical perspectives on soil mapping and process modeling for sustainable land use management Soil Mapp. Process Modeling Sustain. Land Use Manag , (pp. 3-28).

De Vente, J.Reed, M. S., Stringer, L. C., Valente, S., and Newig, J. 2016. "How does the context and design of participatory decision making processes affect their outcomes?" Evidence from sustainable land management in global drylands. Ecol. Soc 21 (2): 4-8

Kapur, S., Eswaran, H., and Blum. 2014.W. "Sustain. land managt: Springer "

Keesstra, S. D., Bouma, J., Wallinga, J., Tittonell, P., Smith, P., Cerdà, A.Van der Putten, W. H. " significance soils soil Sci. towards realization U N. Sustain. Dev. Goals." Soil 2016, 2(2), 111-128.

Kundzewicz, Z., and Kowalczak, P. 2014. "Urban Flooding Sustain. Land Manag.-Pol. Perspect."

Liniger, H., Mekdaschi, R., Moll, P., and Zander, U. 2017."Making sense res. sustain land manag: Centre for Development and Environment (CDE), University of Bern and Helmholtz-Centre for Environmental Research GmbH-UFZ "

Maisharou, A., Chirwa, P., Larwanou, M., Babalola, F., and Ofoegbu, C. 2015. "Sustain. land manag. pract.Sahel: rev. pract. tech. technol. land restor. strategy up-scaling." Int.For Rev 17 (3): 1-19.

Marques, M. J., Bienes, R., Cuadrado, J., Ruiz-Colmenero, M., Barbero-Sierra, C., and Velasco, A. 2015. "Analysing percept. attitudes and responses of winegrowers about sustainable land management in Central Spain." Land degrad. dev 26 (5): 458-467.

Mutoko, M. C., Hein, L., and Shisanya, C. A. '2014. 'Farm diversity, resource use efficiency and sustainable land management in the western highlands of Kenya." J. rural studies 36 (3): 108-120.

Mutoko, E.Mirzabaev, A., \& Von Braun, J .2016. "Econ. land degrad. improv. glob. assess. sustain. dev: Springer"

Plieninger, T.Bieling, C.Fagerholm, N.Byg, A., Hartel, T.Hurley, P.Raymond, C. M. 2015. "The role of cultural ecosystem services in landscape management and planning." Curr. Opin. Environ. Sustain 14 (6): 28-33.

Pereira, P.Brevik, E. C., Muñoz-Rojas, M., Miller, B. A., Smetanova, A., Depellegrin, D.Cerdà, A. 2017. "Soil Mapp. Process. Model. Sustain. Land Manag. Soil mapp. process. modeling sustain'”: land use manag (pp. 29-60).

Pidlisnyuk, V. Erickson, L.Kharchenko, S.\& Stefanovska. 2014. T."Sustainable land management: growing miscanthus in soils contaminated with heavy metals." J. Environ. Protect 5 (8): 723.

Sanz, M.De Vente, J. Chotte, J.-L. Bernoux, M., Kust, G.Ruiz, and Castillo, V. 2017."Sustain. land manag. contrib. success. land-based clim. change adapt. Mitigation',

Reed, M. Stringer, L.Dougill, A.Perkins, J.Atlhopheng, J. Mulale, K., and Favretto, N. 2015. "Reorienting land degradation towards sustainable land management: Linking sustainable livelihoods with ecosystem services in rangeland systems." J. environ. manag 151 (2): 472-485.

Bertin, T., Zacharie, T., Ann, D., Ebenezar, A., and Alain, T. 2014. "Scaling-up sustainable land management practices through the concept of the rural resource centre: reconciling farmers' interests with research agendas." J. of Agric. Educ.Extension 20 (5): 463-483.

Teshome, A., De Graaff, J. Ritsema, C.\& Kassie, M. 2016. "Farmers' perceptions about the influence of land quality, land fragmentation and tenure systems on sustainable land management in the north western Ethiopian Highlands.' Land degrad. dev. 27 (4): 884-898.

Stringer, L.Fleskens, L.Reed, M., De Vente, J. and Zengin, M. 2014. "Participatory evaluation of monitoring and modeling of sustainable land management technologies in areas prone to land degradation." Environ. manag 54 (5): 1022-1042.

Wickama, J.Okoba, B.\& Sterk, G. 2014. "Effectiveness of sustainable land management measures in West Usambara highlands, Tanzania." Catena 118 (2): 91-102.

Wolfgramm, B.Shigaeva, J., and Dear, C. 2015. "The research-action interface in sustainable land management in Kyrgyzstan and Tajikistan: challenges and recommendations." Land degrad. dev 26 (5): 480-490.

Wossen, T. Berger, T.\& Di Falco, S. 2015. "Social capital, risk preference and adoption of improved farm land management practices in Ethiopia." Agric. Econ 46 (1): 81-97.

Zou, J. and Wu, Q. 2017. "Spatial Analysis of Chinese Grain Production for Sustainable Land Management in Plain, Hill, and Mountain Counties"'Sustain 9 (3): 348.

Xie, H.Zou, J.Jiang, H.Zhang, N., and Choi, Y. 2014. "Spatiotemporal pattern and driving forces of arable landuse intensity in China: Toward sustainable land management using emergy analysis." Sustain 6 (6): $3504-$ 3520 . 
Aragon, N. U., Wagner, M., Wang, M., Broadbent, A. M., Parker, N., and Georgescu, M. 2015. "Sustainable land management for bioenergy crops." Energy

Fleskens, L., Nainggolan, D., \& Stringer, L. C. 2014. "An exploration of scenarios to support sustainable land management using integrated.' Proced 20 (17): 379-388.

Barkemeyer, R., Stringer, L. C., Hollins, J. A., \& Josephi, F. "Corporate reporting on solutions to wicked problems: Sustainable land management in the mining sector." Environ. SCI. \& policy 48, 196-209.

Wichelns, D.\& Qadir, M. 2015. "Achieving sustainable irrigation requires effective management of salts, soil salinity, and shallow groundwater." Agric. Water Manag 157 (1): 31-38.

Gunawardana, H., Tantrigoda, D. A., and Kumara, U. 2016. "Humanitarian Demining and Sustainable Land Management in Post-Conflict Settings in Sri-Lanka: Literature Review." J. Mgmt. \& Sustainability, 6 (2): 97.

Popović, V.Miljković, J. Ž.Subić, J.Jean-Vasile, A.Adrian, N.and Nicolăescu, E. 2015. "Sustainable land management in mining areas in Serbia and Romania.” Sustain 7 (9): 11857-11877. 